\title{
Breve análisis morfosintáctico de las expresiones de los periodistas policiales de Lima
}

\section{Morphosyntactic brief analysis of the expressions of journalists police from Lima}

\section{Úrsula Yvonne Velezmoro Contreras ${ }^{1}$}

Universidad SISE

ursulavelezmoro@gmail.com

\section{RESUMEN}

En el presente estudio, se ha registrado el léxico empleado por los periodistas policiales de Lima (LPPL) en la prensa escrita, radial y televisiva. Esta investigación pretende ser útil a las personas ajenas a esta lengua profesional, a fin de que puedan conocer lo que ellos expresan en sus enunciados lingüísticos. Aunque este análisis no contiene todo el LPPL, sí presenta una selección completa de su código. Este trabajo presenta palabras y acepciones que han sido recogidas con significados circunscritos a sus expresiones entre julio y octubre de 2009, entradas que han sido actualizadas desde abril hasta junio de 2016. Se trata de una muestra de casos en los que se observan los procesos morfológicos de derivación, composición, metátesis y supresión, así como la construcción de locuciones adverbiales y verbales, a través de los cuales se forman las palabras de esta lengua profesional.

\section{PALABRAS CLAVE}

Análisis lexicográfico, procesos morfológicos, procesos sintácticos, periodistas policiales, lengua profesional

\section{ABSTRACT}

In the present study it has been registered the lexicon

1 Licenciada en Lingüística por la Universidad Nacional Mayor de San Marcos y con estudios de maestría en Docencia Universitaria en el mismo centro. Autora del ebook y blog de gramática Cuaderno de Estilo, de la página web Clases de Periodismo. Miembro fundador de la Asociación de Correctores de Textos del Perú. Actualmente, es correctora de estilo del Grupo El Comercio y docente en la Universidad Científica del Sur. 
used by the police journalists from Lima (LPPL) in the written press, radial and media. This research pretends to be useful to the people outside this professional language in order that they can know what they expressed in their linguistic utterances. Although, this analysis does not contain the entire LPPL, it does present a complete collection of its code. This work presents words and meanings, which they have been recollected with circumscribed definitions to their expressions between July and October of 2009, entries that have been updated from April to June of 2016. It is a sample of cases where morphological processes of derivation, composition, metathesis and suppression, as well as the construction of adverbial and verbal locutions are observed, as well as the construction of adverbial and verbal locutions, through which the words of this professional language are form.

\section{KEYWORDS}

Lexicographical analysis, morphological processes, syntactic processes, police journalist, professional language

\section{Introducción}

El LPPL es una variedad de lengua profesional y, a la vez, el código que utiliza el periodista policial, el cual surge a partir de la interacción del reportero con el policía y el delincuente, debido a la necesidad del poli$\mathrm{cial}^{2}$ de obtener datos para su nota, reportaje o despacho. El comunicador accede a la información del hecho delictivo por medio del autor del delito o a través de los custodios del orden. De acuerdo con el corpus, que presenta 276 entradas, se parte de la idea de que hay determinados procesos morfológicos y sintácticos que sirven de base para la formación del LPPL.

Según Luis Hernán Ramírez, en Estructura y funcionamiento del lenguaje (1996, p. 146), «las lenguas profesionales son especializaciones de la lengua estándar que corresponden a diferentes ramas de la actividad humana. Cada profesional llega a poseer su propia nomenclatura, con términos, voces y hechos específicos de la profesión, cuyos significados resultan confusos y desconocidos para las personas ajenas a la profesión».

Esta investigación se basa en una muestra del corpus del LPPL, que contiene entradas del lenguaje popular, periodístico y de la jerga del

2 El término policial hace referencia al periodista que cubre la fuente de la sección Policiales. 
periodismo policial; lo cual, a su vez, determina que este pueda ser definido como una variedad de lengua abierta con relación a las entradas que provienen de la lengua popular. Es una variedad de lengua semiabierta ${ }^{3}$ cuando expresa las entradas del léxico periodístico en general y es cerra$\mathrm{da}^{4}$ cuando se refiere única y exclusivamente al léxico que solo emplean los periodistas policiales; mas no los otros comunicadores de las áreas de Política, Cultural, Deportes, Economía, Internacional, Locales, etc.

Como señala Luis Hernán Ramírez, en Estructura y funcionamiento del lenguaje (1996, p. 136), «la lengua popular es la modalidad que más se acerca a la lengua estándar. Corresponde a los hablantes de transición quienes emplean una forma de lengua casi estándar con solo un manejo de formas subestándar. En otros términos, los hablantes de la lengua popular mezclan la forma coloquial con la forma subestándar». Asimismo, Luis Hernán Ramírez, en Estructura y funcionamiento del lenguaje (1996, p.145), sostiene que «entre la lengua común y las especiales no existe un límite claro y preciso. Cualquiera que asome a nuevos campos de la actividad humana participará de las lenguas que corresponden a esos campos en una proporción que depende de sus dotes y habilidades y de la intensidad de su intervención. Entre la lengua común y las especiales existe un continuo intercambio de términos».

\section{Procesos morfológicos}

\section{Derivación ${ }^{5}$ por sufijación}

El proceso morfológico de derivación por sufijación consiste en la formación de palabra por medio de un sufijo. Las palabras que constituyen los datos seleccionados del corpus están formadas mediante el proceso de sufijación, el cual da lugar a dos tipos de derivados: unos que no cambian de categoría u homocategoriales (-ar, -er, -it-, -nche, -ncho) y otros que sí o heterocategoriales (-ad-, -ador, -az-, -ear, -er-, -er-, -iar).

El proceso de sufijación se produce cuando por medio de la recurrencia de determinados sufijos (-ad-, -ador, -ar, -az-, -ear, -er, -er-, -ir, -it-, -iar, -nche, -ncho) se crea otra palabra.

3 La lengua semiabierta es aquella que posee una nomenclatura propia, está vinculada a una profesión y genera cierto grado de dificultad para quien no se desarrolla en dicho campo laboral.

4 La lengua cerrada es aquella que permanece siempre vedada para todos aquellos que no participan de las actividades del sector social que la emplea (Ramírez, 1996, p. 148).

5 El concepto de derivación se refiere a los procedimientos de formación de palabras por medio de afijos (ya sean prefijos, sufijos o interfijos) simples. 


\begin{tabular}{|c|c|}
\hline Sufijo - ad- & Deriva en adjetivo «Sust +- ad- $\rightarrow$ Adj.». \\
\hline \multicolumn{2}{|c|}{$\begin{array}{l}\text { forr }+ \text { ad }+0 \quad \rightarrow \text { forrado } \\
\text { Ese señor estaba forrado, icómo pudo robar! } \\
\text { requisitori }+ \text { ad }+0 \rightarrow \text { requisitoriado } \\
\text { Aunque está requisitoriado, aún no lo capturan. }\end{array}$} \\
\hline Sufijo-ador & Deriva en sustantivo «V + -ador $\rightarrow$ Sust.». \\
\hline \multicolumn{2}{|c|}{$\begin{array}{l}\text { arrebat }+ \text { ador } \rightarrow \text { arrebatador } \\
\text { Solo era arrebatador, pero le encontraron ketes. } \\
\text { descuartiz }+ \text { ador } \rightarrow \text { descuartizador } \\
\text { Detuvieron al descuartizador de station wagon. }\end{array}$} \\
\hline Sufijo-ar & Mantiene su categoría gramatical, pero cambia de significado «V $\rightarrow$ V». \\
\hline \multicolumn{2}{|c|}{ 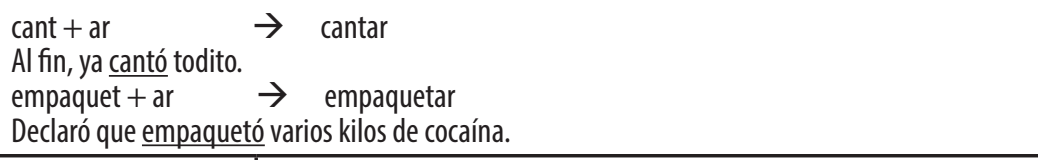 } \\
\hline Sufijo-az- & $\begin{array}{l}\text { Deriva en adjetivo, que también puede ser usado como sustantivo. «Sust. } \\
\rightarrow \text { Adj.» } \text { «Sust. }+-a z-\rightarrow \text { Sust.». }\end{array}$ \\
\hline \multicolumn{2}{|c|}{$\begin{array}{l}\text { plom }+ \text { az }+0 \quad \rightarrow \text { plomazo } \\
\text { Un plomazo perdido lo mató. }\end{array}$} \\
\hline Sufijo-ear & Deriva en verbo «Sust. + -ear $\rightarrow$ V». \\
\hline \multicolumn{2}{|c|}{$\begin{array}{l}\text { calat }+ \text { ear } \\
\text { Los calatearon en la avenida. } \\
\text { can }+ \text { ear } \\
\text { Canearon al pedófilo. }\end{array}$} \\
\hline Sufijo-er & Mantiene su categoría gramatical; pero cambia de significado «V $\rightarrow V »$. \\
\hline \multicolumn{2}{|c|}{$\begin{array}{l}\text { barr }+ \text { er } \quad \rightarrow \text { barrer } \\
\text { Los delincuentes entraron y barrieron. } \\
\text { mov }+ \text { er } \rightarrow \rightarrow \text { mover } \\
\text { Ese narco mueve en el Sur. }\end{array}$} \\
\hline Sufijo -er- & $\begin{array}{l}\text { Deriva en sustantivo; sin embargo, también puede ser usado como adje- } \\
\text { tivo «Sust. } \rightarrow \text { Sust.» } \mathrm{y} \text { «Sust. } \rightarrow \text { Adj.». }\end{array}$ \\
\hline \multicolumn{2}{|c|}{$\begin{array}{l}\text { abort }+ \text { er }+0 \quad \rightarrow \quad \text { abortero } \\
\text { El abortero se escapó de los policías. }\end{array}$} \\
\hline Sufijo-iar & Deriva en verbo «Sust. $\rightarrow$ V». \\
\hline \multicolumn{2}{|c|}{$\begin{array}{l}\text { limp + iar } \quad \rightarrow \quad \text { limpiar } \\
\text { Limpiaron la joyería. } \rightarrow \text { terciar } \\
\text { terc + iar } \\
\text { Esa banda se dedica a terciar. }\end{array}$} \\
\hline \begin{tabular}{|l|l} 
Sufijo-nche & \\
\end{tabular} & Deriva en sustantivo, tiene carácter despectivo «Sust. $\rightarrow$ Sust.». \\
\hline $\begin{array}{l}\text { coma }+ \text { nche } \\
\text { Ese comanche sí te va a } \\
\text { compi }+ \text { nche } \\
\text { El primo era su compinc }\end{array}$ & $\begin{array}{l}\rightarrow \text { comanche } \\
\text { ayudar. } \\
\rightarrow \text { compinche } \\
\text { he. }\end{array}$ \\
\hline
\end{tabular}




\begin{tabular}{|c|c|}
\hline Sufijo-ncho & $\begin{array}{l}\text { En algunos casos, puede derivar en adjetivo y en otros en sustantivo, tie- } \\
\text { ne carácter despectivo «Adj. } \rightarrow \text { Adj.» } y \text { «Sust. } \rightarrow \text { Sust.». }\end{array}$ \\
\hline \multicolumn{2}{|c|}{$\begin{array}{l}\text { fora }+ \text { ncho } \rightarrow \text { forancho } \\
\text { La Policía sospechaba de él por forancho. } \\
\text { coro + ncho } \rightarrow \text { coroncho } \\
\text { El coroncho murió en el accidente. }\end{array}$} \\
\hline Sujifo -it- & $\begin{array}{l}\text { Deriva en sustantivo; además, tiene carácter apreciativo y diminutivo } \\
\text { «Sust. }+ \text {-it- } \rightarrow \text { Sust.». }\end{array}$ \\
\hline \multicolumn{2}{|c|}{$\begin{array}{l}\text { ángel }+ \text { it }+0 \quad \rightarrow \text { angelito } \\
\text { Un angelito cayó en el operativo. } \\
\text { lol }+ \text { it }+ \text { a } \\
\text { Las lolitas fueron las primeras en salir de la cárcel. }\end{array}$} \\
\hline
\end{tabular}

\section{Composición}

Denominamos composición al proceso morfológico por el que dos o más palabras forman conjuntamente una tercera, llamada palabra compuesta o compuesto. En las palabras formadas mediante el proceso de composición, tenemos dos grupos: compuestos que forman una sola palabra y compuestos sintagmáticos.

\begin{tabular}{|l|l|}
\hline \multicolumn{2}{|c|}{ Compuestos que conforman una sola palabra } \\
\hline $\begin{array}{l}\text { V. + Sust. forman un sustantivo «V }+ \\
\text { Sust. } \rightarrow \text { Sust.». }\end{array}$ & $\begin{array}{l}\text { chupa + sangre } \rightarrow \text { chupasangre } \\
\text { El chupasangre se llevó hasta el dinero de su pasaje. } \\
\text { roba }+ \text { casas } \rightarrow \text { robacasas } \\
\text { Los robacasas de San Luis atacaron otra vez. }\end{array}$ \\
\hline $\begin{array}{l}\text { Sust. + Sust. derivan en sustantivo «Sust. } \\
+ \text { Sust. } \rightarrow \text { Sust.». }\end{array}$ & $\begin{array}{l}\text { hombre + araña } \rightarrow \text { hombrearaña } \\
\text { El hombrearaña huyó por el río Rímac. } \\
\text { narco + terruco } \rightarrow \text { narcoterruco } \\
\text { Volvieron a liberar al narcoterruco. }\end{array}$ \\
\hline $\begin{array}{l}\text { Det. + Sust. Derivan en sustantivo; sin } \\
\text { embargo, también puede usarse como } \\
\text { adjetivo «Det. + Sust. } \rightarrow \text { Sust.». }\end{array}$ & $\begin{array}{l}\text { mil }+ \text { caras } \rightarrow \text { milcaras } \\
\text { El milcaras cayó rumbo a Ecuador. }\end{array}$ \\
\hline
\end{tabular}

\section{Compuestos sintagmáticos ${ }^{6}$}

Sust. + Sust. forman un sus- canada + dry $\rightarrow$ canada dry tantivo «Sust. Sust. $\rightarrow$ Sust.». $\quad$ Lo trasladaron a canada dry.

Det. + Sust. forman un sustan- San + George $\rightarrow$ San George

tivo «Det. + Sust. $\rightarrow$ Sust.». $\quad$ Lo pasaron a San George. 


\begin{tabular}{|l|l|}
\hline $\begin{array}{l}\text { Sust. + Sust. +Sust. forman } \\
\text { un sustantivo «Sust. +Sust. }+ \\
\text { Sust. } \rightarrow \text { Sust.». }\end{array}$ & $\begin{array}{l}\text { Perú }+ \text { Nicaragua }+ \text { Perú } \rightarrow \text { Perú Nicaragua Perú (Policía Na- } \\
\text { cional del Perú) } \\
\text { La seguridad estará a cargo de la Perú Nicaragua Perú. }\end{array}$ \\
\hline $\begin{array}{l}\text { Sust. + Adj. forman un sustan- } \\
\text { tivo «Sust. + Adj. } \rightarrow \text { Sust.». }\end{array}$ & $\begin{array}{l}\text { corvina + internacional } \rightarrow \text { corvina internacional } \\
\text { En el hotel, hallaron una corvina internacional. } \\
\text { destrucción }+ \text { civil } \rightarrow \text { destrucción civil } \\
\text { Los detenidos pertenecen a destrucción civil. } \\
\text { fierro }+ \text { hechiza } \rightarrow \text { fierro hechiza } \\
\text { En el penal, incautaron fierro hechiza. }\end{array}$ \\
\hline
\end{tabular}

\section{Metátesis}

El proceso de metátesis produce un cambio de orden en las sílabas de una palabra. En este análisis, se observa que la última sílaba se traslada a posición inicial de palabra y mantiene su misma categoría gramatical. A continuación, algunos ejemplos de este caso.

\begin{tabular}{|c|c|}
\hline Adj. $\rightarrow$ Adj. & 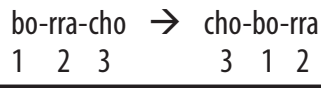 \\
\hline Sust. $\rightarrow$ Sust & 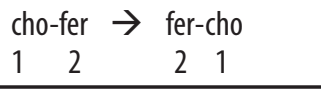 \\
\hline Sust. $\rightarrow$ Sust. & $\begin{array}{llll}\text { ca-mión } & \rightarrow & \text { mion-ca } \\
1 & 2 & 2 & 1\end{array}$ \\
\hline
\end{tabular}

\section{Supresión (acortamiento)}

El proceso de supresión o acortamiento se produce cuando se elide una o más sílabas de una palabra. Este puede observarse al inicio, en medio o al final de la palabra. De acuerdo con las entradas, cada vez que se presente el término no cambiará de categoría gramatical. A continuación, tres tipos de este proceso.

\begin{tabular}{|l|l|}
\hline \multicolumn{2}{|c|}{ Supresión de la sílaba inicial de la palabra } \\
\hline Sust. $\rightarrow$ Sust. & cabrito $\rightarrow$ brito \\
\hline Supresión de las sílabas intermedias de la palabra \\
\hline Sust. $\rightarrow$ Sust. & $\begin{array}{l}\text { patrullero } \rightarrow \text { pato } \\
\text { secuestro } \rightarrow \text { seco }\end{array}$ \\
\hline Supresión de las sílabas finales de la palabra \\
\hline Sust. $\rightarrow$ Sust. & $\begin{array}{l}\text { cocaína } \rightarrow \text { coca } \\
\text { guachimán } \rightarrow \text { guachi }\end{array}$ \\
\hline
\end{tabular}

\section{Categorías gramaticales}

Sustantivo: en esta categoría, se ha encontrado un predominio de los nombres comunes masculinos. 


\begin{tabular}{|l|l|}
\hline \multicolumn{2}{|l|}{ Sustantivo } \\
\hline Nombres comunes & $\begin{array}{l}\text { batería } \\
\text { chaleco } \\
\text { juguete }\end{array}$ \\
\hline Nombres propios & $\begin{array}{l}\text { Dirgén } \\
\text { Luri }\end{array}$ \\
\hline
\end{tabular}

Verbos: en esta categoría gramatical, se ha registrado mayor número de entradas con la terminación -ar.

\begin{tabular}{|l|l|}
\hline Verbos & \\
\hline terminación - ar & adornar \\
& levantar \\
& mancar \\
& pasear \\
\hline
\end{tabular}

Adjetivos: en esta categoría, la mayoría de las entradas son adjetivos derivados de verbos.

\begin{tabular}{|l|l|}
\hline \multicolumn{2}{|l|}{ Adjetivos } \\
\hline Derivados de verbos & $\begin{array}{l}\text { clonado } \\
\text { forrado } \\
\text { negado }\end{array}$ \\
\hline
\end{tabular}

\section{Análisis sintáctico}

Este estudio sintáctico consiste en analizar cómo se componen, combinan y disponen las frases nominales, las frases preposicionales, las locuciones adverbiales y las locuciones verbales.

\section{Locución adverbial ${ }^{7}$}

«Preposición + sigla», esta locución adverbial se presenta con mayor recurrencia después del verbo y siempre en posición final «S $+V+$ Loc. Adv.».

\begin{tabular}{|l|l|l|}
\hline \multicolumn{2}{|c|}{ Locución adverbial } \\
\hline «Preposición + sigla» & $\begin{array}{l}\text { Por+PAF(proyectildearmadefuego) } \\
\text { En + RM (reconocimiento médico) } \\
\text { En + QAP (del inglés Quiet At Phre- } \\
\text { quency) }\end{array}$ & $\begin{array}{l}\text { Su diagnóstico fue muerte por PAF. } \\
\text { La víctima está en RM. } \\
\text { Todos estamos en QAP, jefe. }\end{array}$ \\
\hline
\end{tabular}

7 Según la Nueva gramática de la lengua española, Sintaxis I (2009, p. 599), las locuciones adverbiales son expresiones fijas, constituidas por varias palabras que equivalen a un adverbio. Si bien presentan por lo general una estructura gramaticalmente fija, algunas admiten variantes ortográficas. La mayor parte de las locuciones adverbiales poseen la estructura de un grupo preposicional (preposición + sustantivo o grupo nominal). 


\section{Locuciones verbales ${ }^{8}$}

Según el análisis realizado, la locución verbal «V + Sust.» es la recurrente. A continuación, los diversos tipos de estructuras halladas en esta investigación:

\begin{tabular}{|l|l|l|}
\hline \multicolumn{3}{|l|}{ Locuciones verbales } \\
\hline «V + Sust.» & hacer piñata & Lo hicieron piñata por confesar. \\
\hline «V + Gerund.» & estar caminando & $\begin{array}{l}\text { La información del homicidio del golfista } \\
\text { está caminando. }\end{array}$ \\
\hline «V + Adj.» & estar misio & Jefe, no tiene datos... estoy misio. \\
\hline «V + FN (Det. + Sust.)» & botar el paquete & Antes de que lo detengan, botó el paquete. \\
\hline «V + F. Prep. (Prep. + Sust.)» & ganar a la puerta & Los delincuentes le ganaron a la puerta. \\
\hline «V + F. Prep. (Prep. + Adj.)» & pasar por negado & El detenido pasa por negado. \\
\hline
\end{tabular}

\section{Conclusión}

El estudio lingüístico de las expresiones de los periodistas policiales de Lima determina que para su formación este emplea los procesos morfológicos de derivación, composición, metátesis y supresión. De estos, la derivación por sufijación es la predominante y se manifiesta mediante el uso de dos tipos de sufijos derivativos: unos que no cambian de categoría u homocategoriales (-ar, -er, -it-, -nche, -ncho), como coroncho, y otros que sí o heterocategoriales (-ad-, -ador, -az-, -ear, -er-, -iar), como terciar.

En lo que respecta al proceso de composición, predominan los compuestos que forman una sola palabra «V + Sust. $\rightarrow$ S» (chupasangre). Adicionalmente, en los compuestos sintagmáticos, el tipo más recurrente es «Sust. + Adj. $\rightarrow$ Sust.» (fierro corto). Se hace hincapié en que el significado es fuertemente influido por factores extralingüísticos relacionados con el tipo de noticia.

En el proceso de metátesis, se puede observar que la sílaba ubicada al final de la palabra se traslada a la posición inicial de la misma sin cambiar su categoría gramatical (choborra). En cuanto a la supresión o acortamiento, se evidencia que no hay un cambio de categoría gramatical y es de tres tipos: de sílaba inicial, de sílabas intermedias y de sílaba final, siendo esta última la que más predomina (guachi).

8 Según la Nueva gramática de la lengua española, Sintaxis // (2009, pp. 699-670), son muchas las locuciones verbales que se forman con verbos transitivos. En estas locuciones, se registra considerable variación histórica y geográfica; pero también sintáctica, léxica y —en menor medida - incluso morfológica. Las locuciones verbales se caracterizan, además, por la gran facilidad con que pueden segmentarse y admitir adverbios en su interior. Ello pone de manifiesto que, aunque aparezcan en los diccionarios (en cuanto que son expresiones lexicalizadas), constituyen grupos verbales cuyos componentes muestran cierta autonomía sintáctica. 
De acuerdo con todo el análisis morfológico del corpus, se determina que hay una producción mayor de nombres masculinos, de verbos terminados en -ar, de adjetivos derivados de verbos y de verbos que no cambian de categoría gramatical.

Los procesos sintácticos que contribuyen en la formación de las expresiones de los periodistas policiales de Lima son los que surgen de las locuciones adverbiales «Preposición + sigla» (en RM) y las locuciones verbales «V+Sust.» (meter plomo) que muestran mayor número de entradas.

La variedad de lengua profesional de los periodistas policiales de Lima es semiabierta cuando expresa las entradas del léxico periodístico en general y cerrada cuando se refiere única y exclusivamente al léxico que solo emplean los periodistas policiales.

La construcción de las expresiones de los periodistas policiales se basa en procesos morfosintácticos; no obstante, existen aspectos extralingüísticos que están asociados a su creación (lugar de trabajo, nivel de instrucción de su receptor, duración de la conversación, género, nivel social de las personas involucradas en los hechos policiales: delincuentes y policías). 


\section{REFERENCIAS BIBLIOGRÁFICAS}

Asociación de Academias de la Lengua Española (2010). Diccionarios de americanismos. Lima: Santillana Ediciones Generales.

Martínez de Sousa, J. (1995). Diccionario de lexicografía práctica. Madrid: Biblograf.

Ramírez, L. (1996). Estructura y funcionamiento del lenguaje. Lima: M \& B Editores Impresores.

Real Academia Española (2001). Diccionario de la lengua española. Madrid: Espasa Calpe.

(2005). Diccionario panhispánico de dudas. Bogotá: Santillana Ediciones Generales.

(2009). Nueva gramática de la lengua española. Morfología / Sintaxis I/ Sintaxis II. Madrid: Espasa Libros.

sa Libros.

(2010). Ortografía de la lengua española. España: Espa-

(2014). Diccionario de la lengua española. Bogotá: Es-

pasa Libros.

Seco Reymundo, M. (2003). Estudios de lexicografía española. Madrid: Editorial Gredos Biblioteca Románica Hispánica.

Sifuentes Palma, D. (2007). Gramática del español y competencia lingüística. Lima: Centro de Investigación y Estudios para la Enseñanza Superior José de la Riva-Agüero y Osma.

Solís Fonseca, G. (1994). Introducción en la morfología. Lima: Editorial Libertad. 